J. Dairy Sci. 98:3849-3858

http://dx.doi.org/10.3168/jds.2014-9046

(C) American Dairy Science Association ${ }^{\circledR}, 2015$.

\title{
The effect of intrauterine infusion of dextrose on clinical endometritis cure rate and reproductive performance of dairy cows
}

\author{
V. S. Machado, ${ }^{*}$ G. Oikonomou,† E. K. Ganda, ${ }^{*}$ L. Stephens, ${ }^{*}$ M. Milhomem, ${ }^{*}$ G. L. Freitas, ${ }^{*}$ M. Zinicola, ${ }^{*}$ \\ J. Pearson, ${ }^{*}$ M. Wieland, ${ }^{*}$ C. Guard, ${ }^{*}$ R. O. Gilbert, $\ddagger$ and R. C. Bicalho*1 \\ ${ }^{*}$ Department of Population Medicine and Diagnostic Sciences, College of Veterinary Medicine, Cornell University, Ithaca, NY 14853 \\ †Department of Epidemiology and Population Health, Institute of Infection and Global Health, University of Liverpool, Liverpool L69 7BE, \\ United Kingdom \\ ‡Department of Clinical Sciences, College of Veterinary Medicine, Cornell University, Ithaca, NY 14853
}

\begin{abstract}
The main objective of this study was to evaluate the intrauterine administration use of $200 \mathrm{~mL}$ of $50 \%$ dextrose solution as a treatment against clinical endometritis (CE); CE cure rate and reproductive performance were evaluated. Additionally, the association of several relevant risk factors, such as retained placenta (RP), metritis, CE, anovulation, hyperketonemia, and body condition score with reproductive performance, early embryonic mortality, and CE were evaluated. A total of 1,313 Holstein cows housed on 4 commercial dairy farms were enrolled in the study. At $7 \pm 3$ DIM cows were examined for metritis and had blood collected to determine serum $\beta$-hydroxybutyrate concentration. To determine if cows had ovulated at least once before 44 \pm 3 DIM, the presence of a corpus luteum was evaluated by ovarian ultrasonography at $30 \pm 3$ DIM and at $44 \pm 3$ DIM. At $30 \pm 3$ DIM, CE was diagnosed using the Metricheck device (SimcroTech, Hamilton, New Zealand); cows with purulent or mucopurulent vaginal discharge were diagnosed as having $\mathrm{CE}$. Cows diagnosed with $\mathrm{CE}(\mathrm{n}=175)$ were randomly allocated into 2 treatment groups: treatment (intrauterine infusion of $200 \mathrm{~mL}$ of $50 \%$ dextrose) or control (no infusion). Clinical endometritis cows were re-evaluated as described above at $44 \pm 3$ DIM, and cows that were free of purulent or mucopurulent vaginal discharge were considered cured. Intrauterine infusion of dextrose tended to have a detrimental effect on $\mathrm{CE}$ cure rate, and treatment did not have an effect on first-service conception rate and early embryonic mortality. A multivariable Cox's proportional hazard model was performed to evaluate the effect of several variables on reproductive performance; the variables $\mathrm{RP}, \mathrm{CE}$, parity, anovulation, and the interaction term between parity and anovulation were
\end{abstract}

Received October 30, 2014.

Accepted February 6, 2015.

${ }^{1}$ Corresponding author: rcb28@cornell.edu associated with hazard of pregnancy. Cows that did not have $\mathrm{RP}$ or $\mathrm{CE}$ were more likely to conceive than cows that were diagnosed with RP or CE. Cows that had RP were at 3.36 times higher odds of losing their pregnancy than cows that did not have RP. In addition, cows diagnosed with $\mathrm{CE}$ were at 2.16 higher odds of losing their pregnancy than cows without CE. In conclusion, intrauterine infusion of $200 \mathrm{~mL}$ of $50 \%$ dextrose solution as a treatment for $\mathrm{CE}$ had a strong statistical tendency to decrease $\mathrm{CE}$ cure rate, did not improve first-service conception rate and early embryonic mortality, and did not decrease calving-to-conception interval.

Key words: dextrose, endometritis, uterine health, reproduction

\section{INTRODUCTION}

Reproductive efficiency is of great importance for the dairy industry and significantly affects the overall economic outcome of a dairy enterprise. A healthy reproductive tract is a prerequisite for satisfactory reproductive performance. Clinical endometritis (CE) refers to the presence of purulent or mucopurulent uterine exudates in the vagina occurring after the third week of lactation (Sheldon et al., 2006). Escherichia coli, Trueperella pyogenes, and Fusobacterium necrophorum are the primary bacterial causes of uterine diseases (Miller et al., 2007; Bicalho et al., 2010; Santos et al., 2011). In the first days postpartum, E. coli is the predominant bacterium in the infected uterus and is highly associated with uterine inflammation and impaired reproductive performance (Bondurant, 1999; Bicalho et al., 2012; Machado et al., 2012a). This early uterine contamination with $E$. coli leads to subsequent infection by $F$. necrophorum and T. pyogenes at 7 and $>25 \mathrm{~d}$ postpartum, respectively (Dohmen et al., 2000; Bicalho et al., 2012), which are associated with both metritis (Santos et al., 2011; Bicalho et al., 2012; Machado et al., 2012a) and endometritis (Williams et al., 2005; Machado et al., 2012b). 
In North America, metritis affects 10 to $20 \%$ of cows (LeBlanc et al., 2011). Cows affected with metritis develop moderate to severe illness and are commonly treated with systemic antibiotics, such as penicillin or thirdgeneration cephalosporins with reasonable efficiency (Smith et al., 1998; Drillich et al., 2001; McLaughlin et al., 2012). On the other hand, CE, a disease that affects approximately $28 \%$ of cows, with herd level prevalence ranging from 6.7 to $47.0 \%$ (Bicalho et al., 2010; Dubuc et al., 2011), is not accompanied by systemic signs of illness. However, CE impairs reproductive performance (Barlund et al., 2008; Plontzke et al., 2011), and consequently has a negative economic effect on the modern dairy industry (Lee and Kim, 2007). Many CE treatment strategies have been evaluated to date, such as intrauterine-administered antibiotics (Runciman et al., 2008; Galvão et al., 2009b; McDougall et al., 2013), chlorhexidine (Gilbert and Schwark, 1992), enzymes (Drillich et al., 2005), hypertonic dextrose (Brick et al., 2012), and the systemic administration of $\mathrm{PGF}_{2 \alpha}$ (LeBlanc et al., 2002; Kasimanickam et al., 2005; Lima et al., 2013).

Systemic use of $\mathrm{PGF}_{2 \alpha}$ is one of the most investigated treatments for endometritis, and its efficacy as a CE treatment remains controversial. LeBlanc et al. (2002) reported a detrimental effect of $\mathrm{PGF}_{2 \alpha}$ administration between 20 and 26 DIM to cows that were diagnosed with $\mathrm{CE}$ and did not have a corpus luteum (CL). Kasimanickam et al. (2005) reported that a single dose of $\mathrm{PGF}_{2 \alpha}$ between 22 to 33 DIM improved first-service conception rate (FSCR) and increased the overall hazard of pregnancy. Other studies reported that systemic administration of $\mathrm{PGF}_{2 \alpha}$ did not have any effect on uterine health or reproductive performance (Galvão et al., 2009a; Dubuc et al., 2011; Lima et al., 2013).

The use of intrauterine-administered antibiotics is currently not approved in the United States. However, a single intrauterine infusion of $0.5 \mathrm{~g}$ of cephapirin (first generation cephalosporin) has been reported as an efficacious treatment against CE (Runciman et al., 2008; McDougall et al., 2013). On the other hand, the intrauterine administration of ceftiofur (third generation cephalosporin) was reported to decrease the prevalence intrauterine infection by $T$. pyogenes but did not improve $\mathrm{CE}$ or reproductive performance (Galvão et al., 2009b).

Recently, Brick et al. (2012) suggested a novel treatment for $\mathrm{CE}$; cows diagnosed with $\mathrm{CE}$ were treated with single intrauterine infusion of $200 \mathrm{~mL}$ of a $50 \%$ dextrose solution. It was proposed that the proportion of cows that were clinically cured was higher for treated cows, and the authors suggested that treated cows had increased FSCR. Their hypothesis was that the intrauterine administration of a hypertonic sugar solution would inhibit bacterial growth (Chirife et al., 1983). Consequently, affected cows would recover from infection, mitigating the detrimental effects of endometritis on reproductive performance. Replication of these findings would provide more evidence that intrauterine administration of dextrose could be implemented as a routine practice in the reproductive management of dairy herds.

Therefore, the main objective of this study was to evaluate the effect of intrauterine administration of $50 \%$ dextrose solution on CE cure, FSCR, and early embryonic mortality (EEM). Our secondary objective was to evaluate the association of retained placenta $(\mathbf{R P})$, metritis, CE, anovulation, hyperketonemia (HYK), and BCS with FSCR and EEM at first service, and reproductive performance.

\section{MATERIALS AND METHODS}

\section{Farms and Management}

In this study, 1,313 cows housed on 4 large commercial dairy farms located near Ithaca, New York, were enrolled from May 8, 2013, until July 8, 2013. Farm 1 milked 3,300 cows, farm 2 milked 1,000 cows, farm 3 milked 1,800 cows, and farm 4 milked 1,300 cows. Cows were housed in free-stall barns with concrete stalls covered with mattresses and bedded with manure solids in farm 1, waste paper-pulp in farm 4 , and sand in farms 2 and 3 . Cows were milked 3 times daily in milking parlors and their milk production was automatically recorded on a daily basis. Cow reproductive management was based on a combination of Presynch (Moreira et al., 2001), Ovsynch (Pursley et al., 1995), Resynch (Fricke et al., 2003), and detection of estrus.

\section{Study Design, Case Definition, and Treatments}

Prior to commencement of the study, sample size calculation was performed. We assumed that the $\mathrm{CE}$ cure rate in control cows would be $60 \%$. Considering a $\beta$-value of 0.8 , an $\alpha$ value of 0.05 , and that intrauterine dextrose infusion would increase the cure rate to $75 \%$, a sample size of 165 cows per treatment group was considered sufficient. Based on our assumptions that the CE incidence would be around 30\% (Bicalho et al., 2010; Lima et al., 2013), we evaluated 1,313 cows, which would be sufficient to enroll over 165 cows per treatment group.

Cows were enrolled on a weekly basis; all cows at 7 \pm 3 DIM available during the enrollment period were included in the study. At $7 \pm 3$ DIM, vaginal discharge was retrieved using the Metricheck device (SimcroTech, Hamilton, New Zealand). The presence of fetid, watery, 
red-brown uterine discharge was defined as metritis. Blood was collected from the coccygeal vein/artery using a Vacutainer tube without anticoagulant and a 20 gauge $\times 2.54 \mathrm{~cm}$ Vacutainer needle (Becton, Dickinson and Company, Franklin Lakes, NJ). All blood samples were transported to the laboratory on ice and spun in a centrifuge at $2,000 \times g$ for $15 \mathrm{~min}$ at $4^{\circ} \mathrm{C}$; serum was harvested and frozen at $-80^{\circ} \mathrm{C}$. Serum samples were tested for BHBA concentrations using an electronic BHBA measuring system (Precision Xtra, Abbott, Abingdon, UK) already validated for animal use. (Gordon et al., 2013). Cows with blood BHBA $\geq 1.2$ $\mathrm{mmol} / \mathrm{L}$ were diagnosed as having HYK, as previously reported (McArt et al., 2011). Additionally, BCS were determined for all study cows at $30 \pm 3$ DIM using a 5 -point scale with a quarter-point system (Edmonson et al., 1989).

At $30 \pm 3$ DIM, vaginal discharge was visually evaluated using the Metricheck device. Vaginal discharge was scored using a modified 0 to 5 scale: $0=$ no secretion material retrieved, $1=$ clear mucus, $2=$ flecks of pus in the vaginal discharge, $3=<50 \%$ pus in the vaginal discharge, $4=>50 \%$ pus in the vaginal discharge, 5 $=$ watery, fetid vaginal discharge (McDougall et al., 2007; Dubuc et al., 2010). Cows that had score $\geq 3$ were considered to have CE.

A randomized field trial study design was used; cows diagnosed with $\mathrm{CE}(\mathrm{n}=175)$ were randomly allocated into 2 treatment groups: control and treatment. Cows enrolled in the treatment group received intrauterine infusion of $200 \mathrm{~mL}$ of $50 \%$ dextrose solution; cows were restrained, the perineum area was cleansed and disinfected with $70 \%$ ethanol, and a plastic infusion pipette was introduced into the cranial vagina and manipulated transrectally through the cervix into the uterus. A total of $200 \mathrm{~mL}$ of sterile $50 \%$ dextrose solution was infused into the uterus. Control cows did not receive placebo. Vaginal discharge was re-evaluated at $44 \pm 3$ DIM using the same scoring system previously described. As the definition of clinical cure for $\mathrm{CE}$ is not well established yet; we approached clinical cure as the absence of signs characterizing CE. Therefore, cows that did not have a purulent or mucopurulent vaginal discharge at $44 \pm 3$ DIM (score $<3$ ) were considered cured from CE.

To determine if cows had ovulated at least once before $44 \pm 3$ DIM, ovarian ultrasonography was performed at $30 \pm 3 \mathrm{DIM}$ and at $44 \pm 3$ DIM using a portable ultrasound (Ibex, EI Medical Imaging, Loveland, $\mathrm{CO}$ ) equipped with a $7.5-\mathrm{MHz}$ linear-array transducer. Absence of a visible CL in both examinations was considered anovulation. Cows that were diagnosed with a visible CL at $30 \pm 3$ DIM were not re-evaluated at 44 \pm 3 DIM. Pregnancy was diagnosed on d $30 \pm 3$ postAI via rectal ultrasonography. Pregnancy per AI was calculated as the number of pregnant cows on $\mathrm{d} 30 \pm 3$ divided by the number of cows that were inseminated. Cows diagnosed as pregnant were reexamined $35 \mathrm{~d}$ later for detection of viable pregnancy on d $65 \pm 3$; EEM was defined as the absence of a viable pregnancy on $d$ $65 \pm 3$.

\section{Statistical Analyses}

To facilitate data analysis and interpretation, the variable BCSG (BCSG $=1$ if BCS at $30 \pm 3$ DIM was equal to or less than 2.75; BCSG $=2$ if BCS at $30 \pm$ 3 DIM was greater than 2.75 and equal to or less than 3.25 ; $\mathrm{BCSG}=3$ if $\mathrm{BCS}$ at $30 \pm 3$ DIM was greater than 3.25) was created. Descriptive statistical analyses were undertaken in SAS using the FREQ and MEANS procedures (SAS Institute Inc., Cary, NC).

To assess the effect of treatment on CE cure rate, FSCR, and EEM, 3 logistic models were fitted in SAS using the GLIMMIX procedure. To assess the effect of treatment on likelihood of conceiving, a multivariable Cox's proportional hazard was fitted using the PHREG procedure in SAS. Cows were right-censored if not diagnosed as being pregnant before culling, death, or the end of the data collection period, which was 200 DIM. Treatment (dextrose or control), parity, RP and metritis incidences, HYK, and BCSG were offered to the models. Independent variables and their respective interactions were removed from the models manually and in a stepwise manner when $P<0.10$; the variable treatment was forced into the models even in the absence of statistical significance. Contrasts were performed to compare the effect of treatment versus control, and the effect of $\mathrm{CE}$ (treatment and control cows combined) versus cows not affected with $\mathrm{CE}$ in the logistic regression models. To illustrate the effect of treatment on reproductive performance, a KaplanMeier survival analysis was performed using Medcalc version 12.2.1.0; the Logrank test was used to compute the $P$-value.

To evaluate the effect of each risk factor on FSCR and EEM at first service, 2 groups of logistic models were fitted using the GLIMMIX procedure of SAS. For the first and second group of logistic regression models, the dependent variables were FSCR and EEM at first service, respectively. The independent variables of interest were RP, metritis, CE, anovulation, HYK, and BCSG. Parity and the interaction term between parity and the independent variable of interest were added to all models.

The effect of several variables on reproductive performance was analyzed by a multivariable Cox's proportional hazard using the PHREG procedure in SAS. The independent variables offered to the model included 
parity, BCSG, and RP, metritis, CE, and anovulation incidences. Biologically plausible 2-way interactions were tested; independent variables and their respective interactions were kept when $P<0.10$.

Farm was included under the STRATA statement in the Cox proportional hazard analysis and as a random variable in all other statistical models described above.

\section{RESULTS}

\section{Descriptive Statistics}

Descriptive statistics regarding the incidences of $\mathrm{CE}$, metritis, RP, and anovulation for all cows screened in the study are presented in Table 1 . The incidence of $\mathrm{CE}$ was $14.1 \%$. Therefore, only 175 cows were eligible to be enrolled in the in the field trial. Additionally, descriptive statistics regarding average BCS at treatment, average blood BHBA concentration at $7 \pm 3$ DIM, number of animals enrolled in each farm, and parity of the 175 cows that were randomly allocated into 1 of the 2 treatment groups are presented in Table 2.

\section{Effect of Intrauterine Infusion of Dextrose on CE Cure Rate and Reproduction}

Effects of intrauterine infusion of dextrose on $\mathrm{CE}$ cure rate, FSCR, and EEM at first service are presented in Table 3. Intrauterine infusion of dextrose had a strong tendency to decrease $\mathrm{CE}$ cure rate compared with controls $(P=0.06)$. Control cows were at 1.85 higher odds of being cured than cows treated with intrauterine infusion of dextrose; cure rate was 63.2 and $48.4 \%$, respectively $(P=0.06$, power $=0.52)$. Addi- tionally, treatment did not have an effect on FSCR $(P$ $=0.55$, power $=0.10)$ and EEM at first service $(P=$ 0.82 , power $=0.07$ ). Treatment also did not affect the likelihood of conceiving during the lactation; treated cows were 1.07 times more likely to conceive than control cows $(P=0.74)$. The median calving-to-conception interval for control and dextrose-infused cows was 144 and $159 \mathrm{~d}$, respectively $(P=0.99$, Figure 1$)$.

\section{Effects of RP, Metritis, CE, Anovulation, HYK, and BCS at $30 \pm 3$ DIM on Reproduction}

The effects of RP, metritis, CE, anovulation, HYK, and BCS at $30 \pm 3$ DIM on FSCR and EEM at first service are presented in Table 4 . Cows that did not have RP were at 2.00 increased odds of conceiving at first service than cows that had RP $(P=0.01)$. Additionally, cows that did not have $\mathrm{CE}$ had 1.62 higher odds of conceiving at first service than cows that had CE. Moreover, cows with normal blood BHBA concentration at $7 \pm 3$ DIM tended to have better conception rate at first service than cows diagnosed with HYK; they had 1.30 times higher odds of conceiving than hyperketonemic cows $(P=0.10)$.

Cows that had RP were at 3.36 times higher odds of losing their pregnancy than cows that did not have RP $(P=0.01)$. In addition, cows diagnosed with $\mathrm{CE}$ were at 2.16 higher odds of losing their pregnancy than cows without $\mathrm{CE}(P=0.06)$.

A multivariable Cox's proportional hazard model was performed to evaluate the effect of several variables on reproduction; the variables RP, CE, parity, anovulation, and the interaction term between parity and anovulation were retained in the model (Table

Table 1. Descriptive statistics of 1,313 cows enrolled in the study: incidence of clinical endometritis, metritis, retained placenta, and anovulation by parity and farm

\begin{tabular}{|c|c|c|c|c|c|}
\hline Item & $\mathrm{n}$ & $\begin{array}{l}\text { Incidence } \\
\text { of } \mathrm{CE}^{1}\end{array}$ & $\begin{array}{l}\text { Incidence } \\
\text { of metritis }^{2}\end{array}$ & $\begin{array}{c}\text { Incidence } \\
\text { of } \mathrm{RP}^{3}\end{array}$ & $\begin{array}{c}\text { Incidence } \\
\text { of anovulation }\end{array}$ \\
\hline \multicolumn{6}{|l|}{ Parity } \\
\hline 1 & 537 & 12.3 & 27.9 & 4.5 & 25.3 \\
\hline 2 & 391 & 13.9 & 16.6 & 8.2 & 27.3 \\
\hline$\geq 3$ & 385 & 17.2 & 18.2 & 12.7 & 31.6 \\
\hline Total & 1,313 & 14.1 & 21.7 & 8.0 & 27.7 \\
\hline \multicolumn{6}{|l|}{ Farm } \\
\hline 1 & 651 & 15.7 & 23.2 & 8.1 & 27.4 \\
\hline 2 & 191 & 16.7 & 22.0 & 5.7 & 29.1 \\
\hline 3 & 293 & 11.9 & 20.5 & 7.8 & 26.4 \\
\hline 4 & 178 & 9.8 & 18.0 & 10.1 & 29.4 \\
\hline Total & 1,313 & 14.1 & 21.7 & 8.0 & 27.7 \\
\hline
\end{tabular}

${ }^{1} \mathrm{CE}=$ clinical endometritis, defined as the presence of mucopurulent vaginal discharge retracted using the Metricheck device (SimcroTech, Hamilton, New Zealand).

${ }^{2}$ Metritis, defined as presence of fetid, watery, red-brown uterine discharge at $7 \pm 3$ DIM.

${ }^{3} \mathrm{RP}=$ retained placenta, where cows fail to release their fetal membranes within $24 \mathrm{~h}$ of calving.

${ }^{4}$ Anovulation, defined as the absence of corpus luteum on ultrasonography evaluated at $30 \pm 3$ DIM and 44 \pm 3 DIM. 
Table 2. Descriptive statistics of treatment groups

\begin{tabular}{|c|c|c|c|}
\hline Item $^{1}$ & Control & Dextrose & $P$-value \\
\hline Average blood BHBA concentration $(\mathrm{mmol} / \mathrm{L})$ at $7 \pm 3$ DIM $( \pm \mathrm{SE})$ & $1.28(0.10)$ & $1.25(0.09)$ & 0.80 \\
\hline Enrolled animals on farm $1(\%)$ & $47(49.5)$ & $48(50.5)$ & $0.44^{2}$ \\
\hline Enrolled animals on farm $3(\%)$ & $18(54.5)$ & $15(45.5)$ & \\
\hline Enrolled animals on farm 4 (\%) & $7(41.2)$ & $10(58.8)$ & \\
\hline Enrolled animals in parity $1(\%)$ & $34(54.8)$ & $28(45.2)$ & $0.79^{3}$ \\
\hline Enrolled animals in BCSG $2(\%)$ & $27(52.9)$ & $24(47.1)$ & \\
\hline Enrolled animals in BCSG $3(\%)$ & $10(40.0)$ & $15(60.0)$ & \\
\hline Enrolled animals with RP (\%) & $29(31.9)$ & $16(19.1)$ & 0.05 \\
\hline Enrolled animals with metritis (\%) & $41(45.0)$ & $40(47.6)$ & 0.73 \\
\hline Enrolled animals with HYK (\%) & $35(38.5)$ & $35(41.2)$ & 0.66 \\
\hline Total enrolled animals (\%) & $91(52.0)$ & $84(48.0)$ & \\
\hline
\end{tabular}

${ }^{1}$ BCSG = BCS group; BCS was measured at $30 \pm 3$ DIM, using a 5-point scale with a quarter point system as described by Edmonson et al. (1989). $\mathrm{BCSG}=1(\mathrm{BCS}<2.75) ; \mathrm{BCSG}=2(\mathrm{BCS} \geq 2.75$ and $<3.25)$; and $\mathrm{BCSG}=3(\mathrm{BCS} \geq 3.25)$. RP $=$ retained placenta; HYK $=$ hyperketonemia.

${ }^{2} P$-value applies to enrolled animals on farms 1 to 4 .

${ }^{3} P$-value applies to enrolled animals in parity 1,2 , and $>2$.

${ }^{4} P$-value applies to enrolled animals in BCSG 1,2 , and 3 .

5). Cows that did not have RP were 1.38 times more likely to conceive than cows that had RP $(P=0.04)$. Additionally, cows not diagnosed with $\mathrm{CE}$ were 1.40 times more likely to conceive than cows that had CE $(P<0.01)$. Furthermore, anovulation was only associated with reproductive performance in second parity cows; cows in their second parity that ovulated at least once before $44 \pm 3$ DIM were 1.42 times more likely to conceive than cows in parity 2 that did not ovulate $(P$ $=0.02)$.

\section{DISCUSSION}

The main objective was to evaluate the efficacy of a single intrauterine infusion of $200 \mathrm{~mL}$ of a $50 \%$ dextrose solution in treating $\mathrm{CE}$, and the subsequent effect of this treatment on reproductive performance. Such a treatment was proposed to be effective in a recently published study (Brick et al., 2012). However, in the present study, intrauterine infusion of a hypertonic solution of dextrose tended to be detrimental for uterine health; only $48.4 \%$ of treated cows were cured from endometritis $14 \mathrm{~d}$ after treatment, whereas $63.2 \%$ of control cows were cured from the disease $(P=0.06)$. Additionally, intrauterine dextrose infusion did not have an effect on calving-to-conception interval, FSCR, and EEM at first service. However, some key points should be discussed when comparing our findings with the ones reported by Brick et al. (2012). First, whereas we used the Metricheck device to classify the vaginal

Table 3. The effect of intrauterine infusion of dextrose on clinical endometritis (CE) cure rate, first-service conception rate (FSCR), and early embryonic mortality (EEM) at first service

\begin{tabular}{|c|c|c|c|c|c|c|}
\hline Item & & $\mathrm{n}$ & Cure rate $(\%)$ & Odds ratio $(95 \% \mathrm{CI})$ & \multicolumn{2}{|c|}{$P$-value } \\
\hline $\begin{array}{l}\text { Cows with CE } \\
\text { Cows without CE }\end{array}$ & $\begin{array}{l}\text { Dextrose } \\
\text { Control }\end{array}$ & $\begin{array}{r}84 \\
91 \\
1,065\end{array}$ & $\begin{array}{l}24.9 \\
29.3 \\
39.5\end{array}$ & $\begin{array}{c}\text { Baseline } \\
1.25(0.59-2.62) \\
1.96(1.11-3.48)\end{array}$ & 0.55 & 0.02 \\
\hline $\begin{array}{l}\text { Cows with } \mathrm{CE} \\
\text { Cows without CE }\end{array}$ & $\begin{array}{l}\text { Dextrose } \\
\text { Control }\end{array}$ & $\begin{array}{r}91 \\
84 \\
1,065\end{array}$ & $\begin{array}{l}24.8 \\
21.7 \\
11.8\end{array}$ & $\begin{array}{c}\text { Baseline } \\
0.84(0.18-3.88) \\
0.41(0.12-1.35)\end{array}$ & 0.82 & 0.16 \\
\hline
\end{tabular}

${ }^{1} \mathrm{C} 1=$ contrast 1 , dextrose versus control.

${ }^{2} \mathrm{C} 2=$ contrast 2 , cows without clinical endometritis versus dextrose and control. 


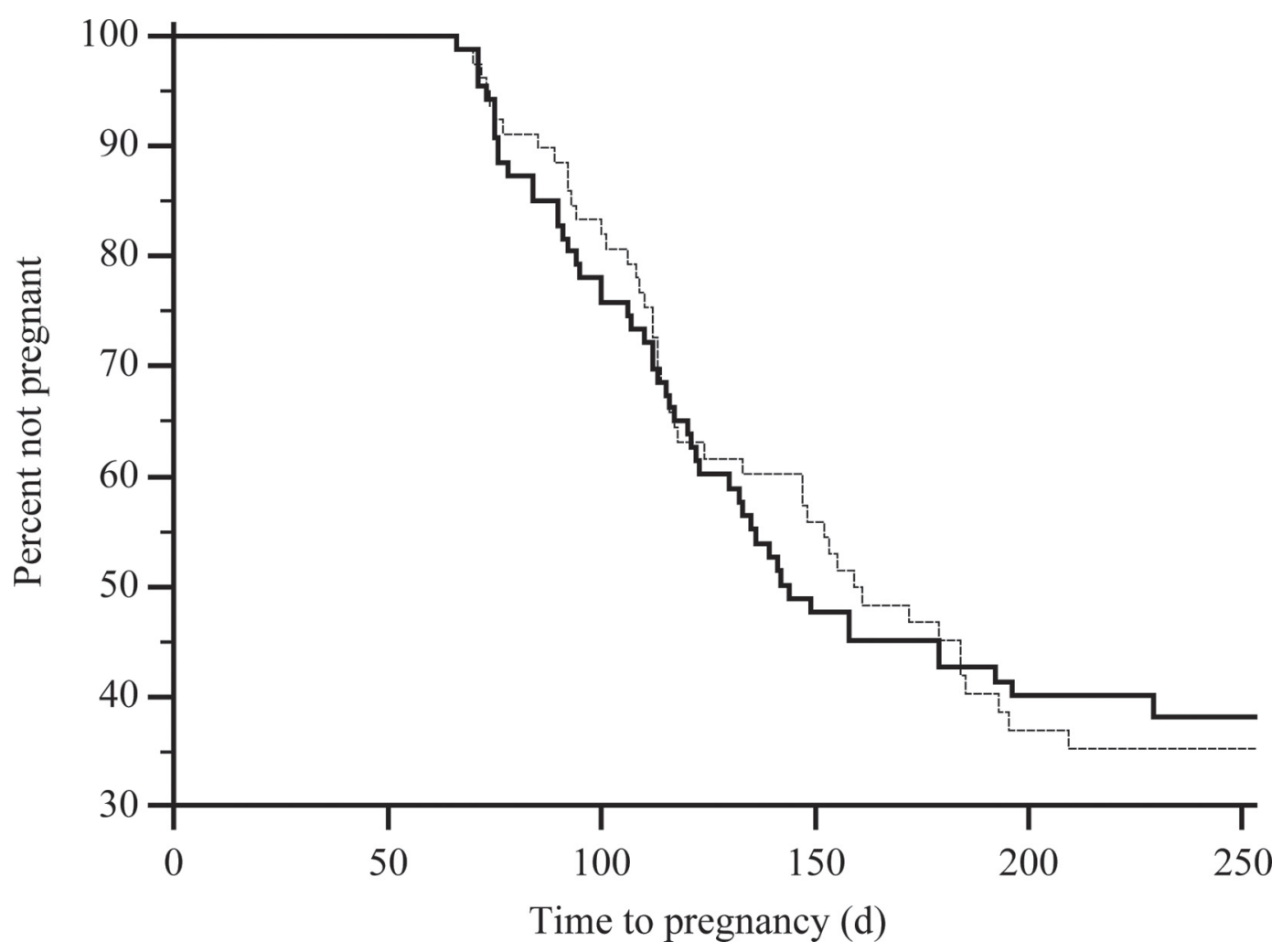

Figure 1. Kaplan-Meier survival analysis of calving-to-conception interval by treatment groups: treatment (intrauterine infusion of $200 \mathrm{~mL}$ of $50 \%$ dextrose, $\mathrm{n}=84$ ) or control (no infusion, $\mathrm{n}=91$ ). The median calving-to-conception interval for control (solid line) and dextrose-infused (dashed line) groups were 144 and $159 \mathrm{~d}$, respectively $(P=0.99)$.

discharge (Dubuc et al., 2010; Bicalho et al., 2010; Lima et al., 2013), Brick et al. (2012) scored the vaginal discharge with the vaginoscopy technique, using a different scoring system. In our study, cows were diagnosed with endometritis when they had any presence of pus beyond flecks in vaginal discharge. In Brick et al. (2012), they used a scoring system that did not take into account vaginal contents composed of less than $50 \%$ purulent content, but with more than only flecks of pus. Therefore, it is unclear if cows with less than $50 \%$ pus, but more than just flecks in vaginal discharge would have been diagnosed with $\mathrm{CE}$, thus being eligible to be enrolled in their study. This variation in CE definition can partially explain the disagreement between the findings regarding the effect of dextrose infusion on clinical cure. Additionally, they defined clinical cure as a cow with $\mathrm{CE}$ (more than $50 \%$ pus in vaginal discharge) before treatment that subsequently had clear mucus $14 \mathrm{~d}$ after treatment; thus, cows with flecks of pus in their vaginal discharge were not considered as cured. Although they observed a beneficial effect of treatment on uterine health, reporting a significant higher proportion of treated cows having clear mucus, after $14 \mathrm{~d}$ of treatment, which could be considered the healthiest mucus score, we believe that, based on their initial definition of $\mathrm{CE}$, cows with flecks of pus should also be classified as clinically cured. It is important to highlight that their results regarding reproductive parameters might have been misinterpreted. Although the proportion of cows that conceived in the first service was numerically higher for cows that received the intrauterine infusion of dextrose when compared with control cows, the $P$-value presented by them was 0.10 . This should be interpreted cautiously as it might lead to a type I statistical error. They admittedly mentioned in their discussion section that more cows diagnosed with $\mathrm{CE}$ would be needed to conclude that the intrauterine dextrose infusion has beneficial effects on FSCR and pregnancy maintenance.

Clinical endometritis incidence in the present study was $14.1 \%$. We performed our original sample size calculations based on an expected a CE prevalence of 20 to $40 \%$ of the study population (Bicalho et al., 2010; Lima et al., 2013) and the lower than expected CE prevalence observed certainly decreased the statistical power of the study. However, despite the unexpectedly low CE incidence, we observed a potentially detrimental effect of dextrose infusion on $\mathrm{CE}$ cure rate $(P=0.06)$. Ad- 
Table 4. The effect of retained placenta, metritis, clinical endometritis, anovulation, hyperketonemia (HYK), and BCS on first-service conception rate (FSCR) and early embryonic mortality (EEM) at first service

\begin{tabular}{|c|c|c|c|c|c|c|c|c|}
\hline \multirow[b]{2}{*}{ Variable } & \multirow[b]{2}{*}{ Level } & \multirow[b]{2}{*}{$\mathrm{n}$} & \multirow{2}{*}{$\begin{array}{c}\text { Adjusted } \\
\text { proportion of } \\
\text { cows pregnant } \\
(\%)\end{array}$} & \multirow{2}{*}{$\begin{array}{l}\text { Adjusted } \\
\text { proportion } \\
\text { of EEM } \\
(\%)\end{array}$} & \multirow{2}{*}{$\begin{array}{c}\text { Odds ratio } \\
(95 \% \mathrm{CI})\end{array}$} & \multicolumn{3}{|c|}{$P$-value } \\
\hline & & & & & & Main $^{1}$ & Parity & Main $\times$ parity \\
\hline \multicolumn{9}{|l|}{ FSCR } \\
\hline \multirow[t]{2}{*}{$\mathrm{RP}^{2}$} & Yes & 105 & 23.9 & - & Baseline & 0.01 & 0.01 & 0.33 \\
\hline & No & 1,208 & 38.8 & - & $2.01(1.15-3.53)$ & & & \\
\hline Metritis $^{3}$ & Yes & 285 & 33.6 & - & Baseline & 0.21 & 0.01 & 0.33 \\
\hline $\mathrm{CE}^{4}$ & No & 1,065 & 39.4 & - & $1.62(1.11-2.37)$ & & & \\
\hline \multirow[t]{2}{*}{ Anovulation $^{5}$} & Yes & 334 & 33.5 & - & Baseline & 0.14 & $<0.01$ & 0.24 \\
\hline & No & 872 & 38.7 & - & $1.25(0.93-1.70)$ & & & \\
\hline \multirow{2}{*}{ HYK $^{6}$} & Yes & 409 & 32.8 & - & Baseline & 0.10 & $<0.01$ & 0.14 \\
\hline & No & 904 & 38.9 & - & $1.30(0.95-1.78)$ & & & \\
\hline \multirow[t]{2}{*}{$\mathrm{BCSG}^{7}$} & 1 & 601 & 34.7 & - & $1.37(0.55-3.42)$ & 0.20 & $<0.01$ & 0.45 \\
\hline & 2 & 421 & 39.8 & - & $1.70(0.68-4.26)$ & & & \\
\hline Metritis $^{3}$ & No & 1,028 & - & 12.4 & Baseline & & & \\
\hline \multirow[t]{2}{*}{$\mathrm{CE}^{4}$} & Yes & 175 & - & 22.3 & $2.16(0.97-4.82)$ & 0.06 & 0.46 & 0.92 \\
\hline & No & 1,065 & - & 11.7 & Baseline & & & \\
\hline \multirow[t]{2}{*}{ Anovulation $^{5}$} & Yes & 334 & - & 12.5 & $1.01(0.42-2.40)$ & 0.98 & 0.07 & 0.19 \\
\hline & No & 872 & - & 12.4 & Baseline & & & \\
\hline \multirow[t]{2}{*}{$\mathrm{HYK}^{6}$} & Yes & 409 & - & 12.8 & $1.02(0.45-2.31)$ & 0.95 & 0.90 & 0.04 \\
\hline & No & 904 & - & 12.5 & Baseline & & & \\
\hline \multirow[t]{3}{*}{$\mathrm{BCSG}^{7}$} & 1 & 601 & - & 13.9 & $2.43(0.52-11.38)$ & 0.52 & 0.24 & - \\
\hline & 2 & 421 & - & 13.4 & $2.33(0.51-10.52)$ & & & \\
\hline & 3 & 214 & - & 6.2 & Baseline & & & \\
\hline
\end{tabular}

${ }^{1} P$-value of the main effect in the model.

${ }^{2} \mathrm{RP}=$ retained placenta, where cows fail to release their fetal membranes within $24 \mathrm{~h}$ of calving.

${ }^{3}$ Metritis $=$ presence of fetid, watery, red-brown uterine discharge at $7 \pm 3$ DIM.

${ }^{4} \mathrm{CE}=$ clinical endometritis, defined as the presence of mucopurulent vaginal discharge retracted using the Metricheck device (SimcroTech, Hamilton, New Zealand).

${ }^{5}$ Anovulation, defined as the absence of corpus luteum on ultrasonography evaluated at $30 \pm 3$ DIM and $44 \pm 3$ DIM.

${ }^{6} \mathrm{HYK}=$ hyperketonemia, defined as BHBA blood concentration equal or greater than $1.2 \mathrm{mmol} / \mathrm{L}$, at $7 \pm 3$ DIM.

${ }^{7} \mathrm{BCSG}=\mathrm{BCS}$ group; BCS was measured at $30 \pm 3$ DIM, using a 5-point scale with a quarter point system as described by Edmonson et al. (1989). $\mathrm{BCSG}=1(\mathrm{BCS}<2.75) ; \mathrm{BCSG}=2(\mathrm{BCS} \geq 2.75$ and $<3.25) ;$ and $\mathrm{BCSG}=3(\mathrm{BCS} \geq 3.25)$.

Table 5. Cox's proportional hazard analysis evaluating the effect of several variables on the hazard of pregnancy; the variables retained placenta, clinical endometritis, parity, anovulation, and the interaction term parity $\times$ anovulation $(P=0.09)$ were retained in the model

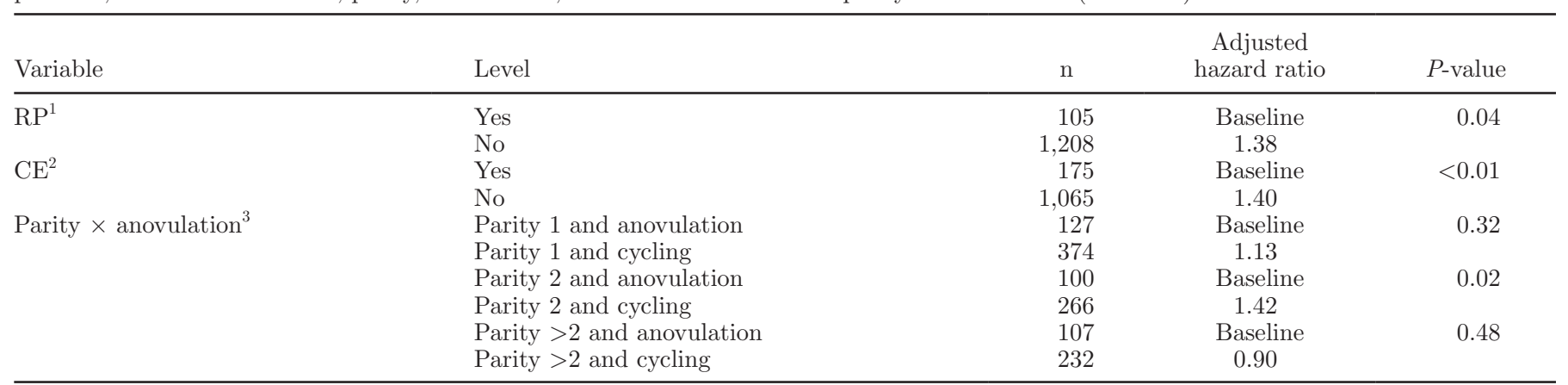

${ }^{1} \mathrm{RP}=$ retained placenta, where cows fail to release their fetal membranes within $24 \mathrm{~h}$ of calving.

${ }^{2} \mathrm{CE}=$ clinical endometritis, defined as the presence of mucopurulent vaginal discharge retracted using the Metricheck device (SimcroTech, Hamilton, New Zealand).

${ }^{3}$ Anovulation, defined as the absence of corpus luteum on ultrasonography evaluated at $30 \pm 3$ DIM and $44 \pm 3$ DIM. 
ditional studies have evaluated the effect of intrauterine infusion of monocarbohydrates on intrauterine health of animals (King et al., 1998; Machado et al., 2012a). It was reported that in mares, intrauterine infusion of mannose decreased the incidence of positive cultures 24 $\mathrm{h}$ after intrauterine challenge with $E$. coli, suggesting that mannose was effective in reducing bacterial infection in the equine endometrium (King et al., 1998). On the other hand, previous work from our group found no effect of intrauterine treatment of $50 \mathrm{~g}$ of mannose at 2 \pm 1 DIM on the incidence of metritis or endometritis, and reproductive performance in dairy cows (Machado et al., 2012a). The rationale for the use of intrauterine treatment of mannose is the inhibition property of this carbohydrate on the adhesion of E. coli onto epithelial surfaces, which is mediated by the type 1 fimbriae adhesive protein FimH (Mooi and de Graaf, 1985; Krogfelt et al., 1990). Previous findings suggest that the fimbriae subunit FimA of T. pyogenes plays an important role in the virulence of $T$. pyogenes to the bovine endometrium (Santos et al., 2010; Bicalho et al., 2012); however, in contrast to FimH, FimA does not possess a carbohydrate binding site (Sharon, 2006). Therefore, it is unreasonable to speculate that dextrose would bind to FimA, inhibiting T. pyogenes to adhere on the uterus epithelial surface. Otherwise, it was suggested that the intrauterine infusion of dextrose might have controlled intrauterine bacterial infection by reducing the water activity (Brick et al., 2012), which is required for bacterial survival (Chirife et al., 1983). The water activity will only be reduced with highly concentrated carbohydrate solutions; perhaps, in our study cows, the intrauterine volume was too large and the dextrose infusion was not sufficient to alter the water activity in the intrauterine environment. In this case, it is also possible that the intrauterine dextrose infusion might have nurtured the intrauterine pathogens, and instead of inhibiting, it might have stimulated their growth. Consequently, the cows' immune systems might have faced a higher load of pathogens in the treated group, failing to eliminate the infection and leading to a decreased $\mathrm{CE}$ cure rate.

The secondary objective of this study was to evaluate the association between several parameters (such as RP, metritis, $\mathrm{CE}$, blood BHBA concentration at 7 \pm 3 DIM, BCS at $30 \pm 3$ DIM, and anovulation) and reproductive performance. Here, we report that RP was an important factor for decreased fertility; cows that had their placenta retained had decreased odds of conceiving at first service $(P=0.01)$, higher odds of embryonic death $(P=0.02)$, and had lower hazard of becoming pregnant throughout their lactation $(P=$ 0.04). Other studies had reported association between $\mathrm{RP}$ and reproductive parameters; it has been reported that RP increased time to first service (Stevens and Dinsmore, 1997), increased services per conception (Holt et al., 1989), increased days open (Melendez et al., 2003), increased first-service EEM (Pereira et al., 2013), and decreased pregnancy rates (McDougall, 2001). Many treatments for RP have been evaluated, such as administration of prostaglandins and oxytocin (Stevens and Dinsmore, 1997), infusion of collagenasecontaining products into the umbilical arteries of RP (Eiler and Hopkins, 1993), and intrauterine ozone flush (Zobel and Tkalcic, 2013). However, they have been shown to be ineffective or impractical. Therefore, RP is still an important uterine disorder, and novel treatments should be evaluated to ameliorate its detrimental effects on fertility of dairy cows.

Anovulation in our study was not associated with first-service EEM $(P=0.98)$, which is not in accordance with many other studies, where anovulation tended to be associated with embryonic death (Galvão et al., 2004; Chebel et al., 2006; Bisinotto et al., 2010). Although FSCR was numerically higher for cyclic cows compared with anovulatory cows, this difference was not significant $(P=0.14)$. Dubuc et al. (2012) also reported that anovulation was not significantly associated with FSCR. Conversely, the majority of previous studies reported that FSCR is significantly lower for anovulatory cows compared with cyclic cows (Walsh et al., 2007; Bisinotto et al., 2010; Galvão et al., 2010). In the present study, survival analysis showed that cyclic cows were more likely to conceive throughout the lactation than anovulatory cows. However, this detrimental effect of anovulation was conditional to parity. Anovulation was associated with lower hazards of pregnancy only in cows in parity $2(P=0.02)$; for primiparous cows, and cows in parity greater than 2 , anovulation was not statistically associated with hazards of pregnancy $(P=0.32$ and 0.48 , respectively). A previous study had also reported a detrimental effect conditional to parity of anovulation on the likelihood of conceiving during the lactation (Dubuc et al., 2012). Unlike our findings, they reported that the detrimental effect of anovulation on likelihood of conceiving was only important for cows in parity $>2$. A conditional effect of parity was not observed by Galvão et al. (2010).

Metritis was not associated with impaired fertility in our study; here, metritis was defined as the presence of fetid, watery, red-brown uterine discharge, regardless of fever. It has been recently published that only cows diagnosed with puerperal metritis (foul uterine discharge followed by fever) had impaired reproductive performance, whereas cows diagnosed with clinical metritis (foul uterine discharge not followed by systemic signs) and healthy cows had similar reproductive performance (Giuliodori et al., 2013). Perhaps, if fever was 
part of our case definition for metritis, we could have observed detrimental effects of puerperal metritis in fertility. On the other hand, CE, another postpartum uterine disease, was associated with decreased FSCR at first service $(P=0.01)$, decreased hazard of becoming pregnant during the lactation $(P<0.01)$, and tended to be associated with increased embryonic mortality $(P$ $=0.06)$. Many other studies have previously reported the detrimental effects of endometritis on reproductive performance of dairy cows; it has been associated with lower first-service pregnancy risk (Dubuc et al., 2011), increased calving-to-conception interval (Dubuc et al., 2010), and increased services per conception and embryonic mortality (Lima et al., 2013).

In conclusion, intrauterine infusion of a $50 \%$ dextrose solution failed to cure $\mathrm{CE}$ and had no effect on FSCR, pregnancy maintenance, and calving-to-conception interval. Further research is needed to develop and evaluate a proper treatment to cure $\mathrm{CE}$ and ameliorate the detrimental effect of this disease on the reproductive performance of dairy cows.

\section{ACKNOWLEDGMENTS}

This project was partially supported by Agriculture and Food Research Initiative Competitive Grant (201368004-20361) from the USDA National Institute of Food and Agriculture (Washington, DC).

\section{REFERENCES}

Barlund, C. S., T. D. Carruthers, C. L. Waldner, and C. W. Palmer. 2008. A comparison of diagnostic techniques for postpartum endometritis in dairy cattle. Theriogenology 69:714-723.

Bicalho, M. L., V. S. Machado, G. Oikonomou, R. O. Gilbert, and R. C. Bicalho. 2012. Association between virulence factors of Escherichia coli, Fusobacterium necrophorum, and Arcanobacterium pyogenes and uterine diseases of dairy cows. Vet. Microbiol. 157:125-131.

Bicalho, R. C., V. S. Machado, M. L. Bicalho, R. O. Gilbert, A. G. Teixeira, L. S. Caixeta, and R. V. Pereira. 2010. Molecular and epidemiological characterization of bovine intrauterine Escherichia coli. J. Dairy Sci. 93:5818-5830.

Bisinotto, R. S., R. C. Chebel, and J. E. Santos. 2010. Follicular wave of the ovulatory follicle and not cyclic status influences fertility of dairy cows. J. Dairy Sci. 93:3578-3587.

Bondurant, R. H. 1999. Inflammation in the bovine female reproductive tract. J. Anim. Sci. 77(Suppl. 2):101-110.

Brick, T. A., G. M. Schuenemann, S. Bas, J. B. Daniels, C. R. Pinto, D. M. Rings, and P. J. Rajala-Schultz. 2012. Effect of intrauterine dextrose or antibiotic therapy on reproductive performance of lactating dairy cows diagnosed with clinical endometritis. J. Dairy Sci. 95:1894-1905.

Chebel, R. C., J. E. Santos, R. L. Cerri, H. M. Rutigliano, and R. G. Bruno. 2006. Reproduction in dairy cows following progesterone insert presynchronization and resynchronization protocols. J. Dairy Sci. 89:4205-4219.

Chirife, J., L. Herszage, A. Joseph, and E. S. Kohn. 1983. In vitro study of bacterial growth inhibition in concentrated sugar solutions: Microbiological basis for the use of sugar in treating infected wounds. Antimicrob. Agents Chemother. 23:766-773.
Dohmen, M. J., K. Joop, A. Sturk, P. E. Bols, and J. A. Lohuis. 2000. Relationship between intra-uterine bacterial contamination, endotoxin levels and the development of endometritis in postpartum cows with dystocia or retained placenta. Theriogenology 54:1019-1032.

Drillich, M., O. Beetz, A. Pfutzner, M. Sabin, H. J. Sabin, P. Kutzer, H. Nattermann, and W. Heuwieser. 2001. Evaluation of a systemic antibiotic treatment of toxic puerperal metritis in dairy cows. J. Dairy Sci. 84:2010-2017.

Drillich, M., D. Raab, M. Wittke, and W. Heuwieser. 2005. Treatment of chronic endometritis in dairy cows with an intrauterine application of enzymes. A field trial. Theriogenology 63:1811-1823.

Dubuc, J., T. F. Duffield, K. E. Leslie, J. S. Walton, and S. J. LeBlanc. 2010. Definitions and diagnosis of postpartum endometritis in dairy cows. J. Dairy Sci. 93:5225-5233.

Dubuc, J., T. F. Duffield, K. E. Leslie, J. S. Walton, and S. J. Leblanc. 2011. Randomized clinical trial of antibiotic and prostaglandin treatments for uterine health and reproductive performance in dairy cows. J. Dairy Sci. 94:1325-1338.

Dubuc, J., T. F. Duffield, K. E. Leslie, J. S. Walton, and S. J. LeBlanc. 2012. Risk factors and effects of postpartum anovulation in dairy cows. J. Dairy Sci. 95:1845-1854.

Edmonson, A. J., I. J. Lean, L. D. Weaver, T. Farver, and G. Webster. 1989. A body condition scoring chart for Holstein dairy cows. J. Dairy Sci. 72:68-78.

Eiler, H., and F. M. Hopkins. 1993. Successful treatment of retained placenta with umbilical cord injections of collagenase in cows. J. Am. Vet. Med. Assoc. 203:436-443.

Fricke, P. M., D. Z. Caraviello, K. A. Weigel, and M. L. Welle. 2003. Fertility of dairy cows after resynchronization of ovulation at three intervals following first timed insemination. J. Dairy Sci. 86:3941-3950.

Galvão, K. N., M. Frajblat, S. B. Brittin, W. R. Butler, C. L. Guard, and R. O. Gilbert. 2009a. Effect of prostaglandin F2alpha on subclinical endometritis and fertility in dairy cows. J. Dairy Sci. 92:4906-4913.

Galvão, K. N., M. Frajblat, W. R. Butler, S. B. Brittin, C. L. Guard, and R. O. Gilbert. 2010. Effect of early postpartum ovulation on fertility in dairy cows. Reprod. Domest. Anim. 45:e207-e211.

Galvão, K. N., L. F. Greco, J. M. Vilela, M. F. Sa Filho, and J. E. Santos. 2009b. Effect of intrauterine infusion of ceftiofur on uterine health and fertility in dairy cows. J. Dairy Sci. 92:1532-1542.

Galvão, K. N., J. E. Santos, S. O. Juchem, R. L. Cerri, A. C. Coscioni, and M. Villasenor. 2004. Effect of addition of a progesterone intravaginal insert to a timed insemination protocol using estradiol cypionate on ovulation rate, pregnancy rate, and late embryonic loss in lactating dairy cows. J. Anim. Sci. 82:3508-3517.

Gilbert, R. O., and W. S. Schwark. 1992. Pharmacologic considerations in the management of peripartum conditions in the cow. Vet. Clin. North Am. Food Anim. Pract. 8:29-56.

Giuliodori, M. J., R. P. Magnasco, D. Becu-Villalobos, I. M. LacauMengido, C. A. Risco, and R. L. de la Sota. 2013. Metritis in dairy cows: Risk factors and reproductive performance. J. Dairy Sci. 96:3621-3631.

Gordon, J. L., S. J. LeBlanc, and T. F. Duffield. 2013. Evaluation of accuracy of an electronic $\beta$-hydroxybutyrate meter using fresh and stored whole blood and serum from dairy cows. J. Dairy Sci. 96 (E-Suppl. 1):55-56. (Abstr.)

Holt, L. C., W. D. Whittier, F. C. Gwazdauskas, and W. E. Vinson. 1989. Early postpartum reproductive profiles in Holstein cows with retained placenta and uterine discharges. J. Dairy Sci. 72:533539.

Kasimanickam, R., T. F. Duffield, R. A. Foster, C. J. Gartley, K. E. Leslie, J. S. Walton, and W. H. Johnson. 2005. The effect of a single administration of cephapirin or cloprostenol on the reproductive performance of dairy cows with subclinical endometritis. Theriogenology 63:818-830.

King, S. S., E. M. Carnevale, L. G. Nequin, and J. J. Crawford. 1998. Inhibition of bacterial endometritis with mannose. J. Equine Vet. Sci. $18: 332-334$. 
Krogfelt, K. A., H. Bergmans, and P. Klemm. 1990. Direct evidence that the FimH protein is the mannose-specific adhesin of Escherichia coli type 1 fimbriae. Infect. Immun. 58:1995-1998.

LeBlanc, S. J., T. F. Duffield, K. E. Leslie, K. G. Bateman, G. P. Keefe, J. S. Walton, and W. H. Johnson. 2002. The effect of treatment of clinical endometritis on reproductive performance in dairy cows. J. Dairy Sci. 85:2237-2249.

LeBlanc, S. J., T. Osawa, and J. Dubuc. 2011. Reproductive tract defense and disease in postpartum dairy cows. Theriogenology 76:1610-1618.

Lee, J. I., and I. H. Kim. 2007. Pregnancy loss in dairy cows: The contributing factors, the effects on reproductive performance and the economic impact. J. Vet. Sci. 8:283-288.

Lima, F. S., R. S. Bisinotto, E. S. Ribeiro, L. F. Greco, H. Ayres, M. G. Favoreto, M. R. Carvalho, K. N. Galvão, and J. E. Santos. 2013. Effects of 1 or 2 treatments with prostaglandin $\mathrm{F}(2)$ alpha on subclinical endometritis and fertility in lactating dairy cows inseminated by timed artificial insemination. J. Dairy Sci. 96:6480-6488.

Machado, V. S., M. L. Bicalho, R. V. Pereira, L. S. Caixeta, J. H. Bittar, G. Oikonomou, R. O. Gilbert, and R. C. Bicalho. 2012a. The effect of intrauterine administration of mannose or bacteriophage on uterine health and fertility of dairy cows with special focus on Escherichia coli and Arcanobacterium pyogenes. J. Dairy Sci. 95:3100-3109.

Machado, V. S., G. Oikonomou, M. L. Bicalho, W. A. Knauer, R. Gilbert, and R. C. Bicalho. 2012b. Investigation of postpartum dairy cows' uterine microbial diversity using metagenomic pyrosequencing of the 16S rRNA gene. Vet. Microbiol. 159:460-469.

McArt, J. A., D. V. Nydam, P. A. Ospina, and G. R. Oetzel. 2011. A field trial on the effect of propylene glycol on milk yield and resolution of ketosis in fresh cows diagnosed with subclinical ketosis. J. Dairy Sci. 94:6011-6020.

McDougall, S. 2001. Effect of intrauterine antibiotic treatment on reproductive performance of dairy cows following periparturient disease. N. Z. Vet. J. 49:150-158.

McDougall, S., M. de Boer, C. Compton, and S. J. Leblanc. 2013. Clinical trial of treatment programs for purulent vaginal discharge in lactating dairy cattle in New Zealand. Theriogenology 79:1139-1145.

McDougall, S., R. Macaulay, and C. Compton. 2007. Association between endometritis diagnosis using a novel intravaginal device and reproductive performance in dairy cattle. Anim. Reprod. Sci. 99:9-23.

McLaughlin, C. L., E. Stanisiewski, M. J. Lucas, C. P. Cornell, J. Watkins, L. Bryson, J. K. Tena, J. Hallberg, and J. R. Chenault. 2012. Evaluation of two doses of ceftiofur crystalline free acid sterile suspension for treatment of metritis in lactating dairy cows. J. Dairy Sci. 95:4363-4371.

Melendez, P., G. A. Donovan, C. A. Risco, R. Littell, and J. P. Goff. 2003. Effect of calcium-energy supplements on calving-related disorders, fertility and milk yield during the transition period in cows fed anionic diets. Theriogenology 60:843-854.

Miller, A. N., E. J. Williams, K. Sibley, S. Herath, E. A. Lane, J. Fishwick, D. M. Nash, A. N. Rycroft, H. Dobson, C. E. Bryant, and I. M. Sheldon. 2007. The effects of Arcanobacterium pyogenes on endometrial function in vitro, and on uterine and ovarian function in vivo. Theriogenology 68:972-980.

Mooi, F. R., and F. K. de Graaf. 1985. Molecular biology of fimbriae of enterotoxigenic Escherichia coli. Curr. Top. Microbiol. Immunol. 118:119-138.

Moreira, F., C. Orlandi, C. A. Risco, R. Mattos, F. Lopes, and W. W. Thatcher. 2001. Effects of presynchronization and bovine somatotropin on pregnancy rates to a timed artificial insemination protocol in lactating dairy cows. J. Dairy Sci. 84:1646-1659.

Pereira, R. V., L. S. Caixeta, J. O. Giordano, C. L. Guard, and R. C. Bicalho. 2013. Reproductive performance of dairy cows resynchronized after pregnancy diagnosis at 31 ( \pm 3 days) after artificial insemination (AI) compared with resynchronization at 31 ( \pm 3 days) after AI with pregnancy diagnosis at 38 ( \pm 3 days) after AI. J. Dairy Sci. 96:7630-7639.

Plöntzke, J., L. Madoz, R. De la Sota, W. Heuwieser, and M. Drillich. 2011. Prevalence of clinical endometritis and its impact on reproductive performance in grazing dairy cattle in Argentina. Reprod. Domest. Anim. 46:520-526.

Pursley, J. R., M. O. Mee, and M. C. Wiltbank. 1995. Synchronization of ovulation in dairy cows using PGF2alpha and GnRH. Theriogenology 44:915-923.

Runciman, D. J., G. A. Anderson, J. Malmo, and G. M. Davis. 2008 Effect of intrauterine treatment with cephapirin on the reproductive performance of seasonally calving dairy cows at risk of endometritis following periparturient disease. Aust. Vet. J. 86:250-258.

Santos, T. M., L. S. Caixeta, V. S. Machado, A. K. Rauf, R. O. Gilbert, and R. C. Bicalho. 2010. Antimicrobial resistance and presence of virulence factor genes in Arcanobacterium pyogenes isolated from the uterus of postpartum dairy cows. Vet. Microbiol. 145:84-89.

Santos, T. M., R. O. Gilbert, and R. C. Bicalho. 2011. Metagenomic analysis of the uterine bacterial microbiota in healthy and metritic postpartum dairy cows. J. Dairy Sci. 94:291-302.

Sharon, N. 2006. Carbohydrates as future anti-adhesion drugs for infectious diseases. Biochim. Biophys. Acta 1760:527-537.

Sheldon, I. M., G. S. Lewis, S. LeBlanc, and R. O. Gilbert. 2006 Defining postpartum uterine disease in cattle. Theriogenology 65:1516-1530.

Smith, B. I., G. A. Donovan, C. Risco, R. Littell, C. Young, L. H. Stanker, and J. Elliott. 1998. Comparison of various antibiotic treatments for cows diagnosed with toxic puerperal metritis. J. Dairy Sci. 81:1555-1562.

Stevens, R. D., and R. P. Dinsmore. 1997. Treatment of dairy cows at parturition with prostaglandin F2 alpha or oxytocin for prevention of retained fetal membranes. J. Am. Vet. Med. Assoc. 211:1280-1284.

Walsh, R. B., D. F. Kelton, T. F. Duffield, K. E. Leslie, J. S. Walton, and S. J. LeBlanc. 2007. Prevalence and risk factors for postpartum anovulatory condition in dairy cows. J. Dairy Sci. 90:315-324.

Williams, E. J., D. P. Fischer, D. U. Pfeiffer, G. C. England, D. E. Noakes, H. Dobson, and I. M. Sheldon. 2005. Clinical evaluation of postpartum vaginal mucus reflects uterine bacterial infection and the immune response in cattle. Theriogenology 63:102-117.

Zobel, R., and S. Tkalcic. 2013. Efficacy of ozone and other treatment modalities for retained placenta in dairy cows. Reprod. Domest. Anim. 48:121-125. 